\title{
Ploidy Identification and Analysis of Saccharum and Its Related Genera
}

Gui Yiyun *, Zhang Ronghua *, Liu Xihui *, Wei Jinju, Zhou Hui, Li Haibi, Zhang Xiaoqiu, Qu Huiping, Huang Dongliang $₫$, Li Yangrui ${ }^{*}$

Key Laboratory of Sugarcane Biotechnology and Genetic Improvement (Guangxi), Ministry of Agriculture, Guangxi Key Laboratory of Sugarcane Genetic Improvement, Sugarcane Research Center of Chinese Academy of Agricultural Sciences, Sugarcane Research Institute of Guangxi Academy of Agricultural Sciences, Nanning, 530007, China

* These authors contributed equally to this work

ॠ Corresponding author Email: hd1666@163.com; $\underline{\text { liyr@gxaas.net }}$

Molecular Plant Breeding, 2019, Vol.10, No.12 doi: $10.5376 / \mathrm{mpb} .2019 .10 .0012$

Received: 08 Aug., 2019

Accepted: 03 Sep., 2019

Published: 12 Sep., 2019

Copyright (C) 2019 Gui et al., This article was first published in Molecular Plant Breeding (2018, 16(15): 5100-5107) in Chinese, and here was authorized to translate and publish the paper in English under the terms of Creative Commons Attribution License, which permits unrestricted use, distribution, and reproduction in any medium, provided the original work is properly cited.

Preferred citation for this article:

Gui Y.Y., Zhang R.H., Liu X.H., Wei J.J., Zhou H., Li H.B., Zhang X.Q., Ou H.P., Huang D.L., and Li Y.R., 2018, Ploidy identification and Analysis of Saccharum and its related genera, Molecular Plant Breeding, 10(12): 93-99 (doi: 10.5376/mpb.2019.10.0012)

\begin{abstract}
In order to provide basis for the genetic improvement efficiency of sugarcane, and to find out the ploidy of sugarcane and its related genera and cultivated species, the ploidy of sugarcane and its related genera was systematically analyzed and identified by flow cytometry for the first time in this study. The results showed that the ploidy of the tropical species of Saccharum was 8 and 10 , in which the ploidy of typical tropical species Badila was 8 and that of atypical tropical species Kala Wa was 10 . The ploidy of $S$. barberry was 8 and 16.8, and the ploidy of Mungo was 8 and that of Pansahi was 16. The ploidy of $S$. sinense Yuba and reed cane was 9.8 and 10, respectively. The ploidy of $S$. spontaneum was $6.3 \sim 9.2$ and most of them were about 8 , while the ploidy of $S$. robustum was 14.4. The ploidy of Erianthus, the related genera of Saccharum, was 3.3 7.9, and the ploidy of $S$. arundinaceum and Erianthus rockii was 7.1 7.9 and 3.3 3.8, respectively. There were two kinds of ploidy in Miscanthus (1.4 and 4.8) and the ploidy of Narenga was 3.6 5.2. The ploidy of hybrid cultivars of Saccharum was relatively higher, which was 8.2 12.3, and ploidy of 9 10 was the most common. The ploidy of Saccharum and its related genera and cultivated species was systematically proved for the first time in this research, and the lowest ploidy was in Miscanthus (1.4) and the highest ploidy was in Pansahi (16.8), indicating that Saccharum was an aneuploid plant with complex genetic background. The results of this study could be used to guide the configuration of sugarcane hybrid combinations.
\end{abstract}

Keywords Saccharum, Related genera, Ploidy identification, Flow cytometry

\section{Background}

Sugarcane is not only an important sugar crop in China, but also an important energy crop. With the continuous improvement of national living standards, people's demand for sugar consumption is also increasing. Sugarcane industry will play a more important role in the development of Chinese economy and society in the future. China's sugarcane producing areas are mainly concentrated in Guangxi, Yunnan, Guangdong, Hainan and Fujian (Li, 2010, China Agriculture Press, pp.102-156; Chen et al., 2015; Li et al., 2015; Xu et al., 2015; Li et al., 2016). Among them, Guangxi has the largest planting area, accounting for more than $65 \%$ of the national area, followed by Yunnan and Guangdong (Liu et al., 2017).

Saccharum belongs to Gramineae, Andropogoneae, Saccharinae, which is a $\mathrm{C}_{4}$ high photosynthetic capacity plant. It contains six protospecies, including $S$. officinarum, $S$. barberi, $S$. sinense, $S$. spontaneum, $S$. robustum and $S$. edule. Among them, $S$. edule does little to the breeding of Saccharum. The related genera of Saccharum mainly contain Erianthus Michx., Sclerostachya (Hach.) A. Camus, Narenga Bor, Miscanthus Anderss et al., which are the main sources of Saccharum resistance. These related genera are collectively referred to as "Saccharum complex" together with Saccharum (Grivet and Arruda, 2001; Cai et al., 2002; Li, 2010, China Agriculture Press, pp.102-156; Liu et al., 2012a; 2012b).

Ploidy identification is an important link in ploidy breeding and application. Understanding plant ploidy can 
effectively reduce blindness in breeding and accelerate the breeding process ( $\mathrm{Li}$ et al. 2010, China Agriculture Press, pp.102-156). The methods of plant ploidy identification mainly include morphological identification, physiological and biochemical identification, fertility status identification, cytological identification, molecular level identification and so on. Sugarcane is an aneuploid heteroploidy plant with very complex heredity, many chromosomes and huge genome. The number of chromosomes varies greatly among different species or different types within the same species. $2 \mathrm{n}=100 \sim 130$. It mainly contains three kindreds, which are $S$. spontaneum, $S$. officinarum and S. barberi (Grivet and Arruda, 2001; Li, 2010, China Agriculture Press, pp.102-156; Wang et al., 2015a; Hu et al., 2016). The genetic behaviors of sugarcane chromosomes are $n+n, n+2 n, 2 n+n$ and $2 n+2 n$, with complex transmission mode. Also, $\mathrm{n}$ often changes, which is not the original number of ploidy and is accompanied by increase or decrease. That is to say, "Unbalanced Inheritance" phenomenon occurs (Bremer, 1924; Huang et al. 2015). Therefore, compared with other homozygous crops, it is difficult to accurately identify sugarcane ploidy by conventional phenotypic analysis and cytological identification in the practical work of sugarcane breeding. At present, the studies on ploidy identification of sugarcane at home and abroad are only found in the typical tropical species Badila, which is an octoploid and 2n=10x=80 (Whalen, 1991; Irvine, 1999; Wang et al. 2008; Wang et al. 2015b). Ploidy identification of other sugarcane species and related genera has not been reported.

Flow cytometry (FCM) is a technique developed in 1970s. It is a method of molecular level identification. It mainly analyzes a large number of cells in tissues and determines the DNA content of isolated nuclei, as well as the DNA content of crops increases with the increase of ploidy, so as to judge the ploidy level. Flow cytometry is not limited by the sampling site and the cell stage, which is simple, sensitive, accurate and reproducible. It can rapidly detect the ploidy of plant (Jin et al., 2016). Up to now, flow cytometry has been widely used in ploidy analysis of rice (Tan et al., 2014), Magnolia liliflora (Zhao et al., 2016), mulberry (Yanget al., 2017) and other crops. In this study, the ploidy of sugarcane and its related genera was systematically identified and analyzed by flow cytometry for the first time in order to provide theoretical basis and scientific basis for conventional sugarcane breeding and distant cross utilization of germplasm resources, especially wild germplasm resources.

\section{Results and Analysis}

\subsection{Ploidy identification of Saccharum}

In this study, the typical tropical species Badila ( $2 n=80$, octaploid) was set as the control to identify the ploidy of Saccharum materials. Among them, the ploidy of the atypical tropical species Kala Wa, S. barberry Mungo and Pansahi was 10, 8 and 16.8, respectively; The ploidy of $S$. sinense Uba and Luzhe was 9.8 and 10; The ploidy of GSM56, GSM84-24, GSM85-2 and GSM79-9 in S. spontaneum was 7.7, 8.6, 9.2 and 6.3, respectively. The ploidy of both Yacheng S. spontaneum 12 and Fujian S. spontaneum 2 was 8; The ploidy of S. robustum was 14.4 (Figure 1; Table 1).

\subsection{Ploidy identification of the related genera of sugarcane}

From the data of ploidy detection (Table 1), we can see that among the related genera of sugarcane, the ploidy of

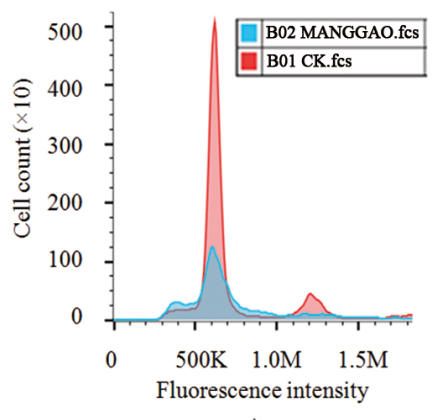

A

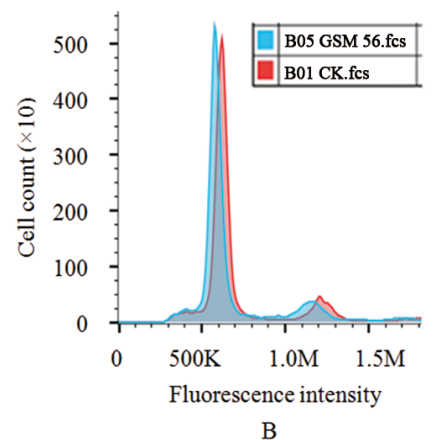

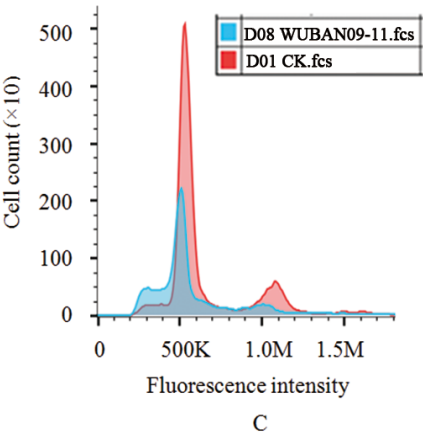

C

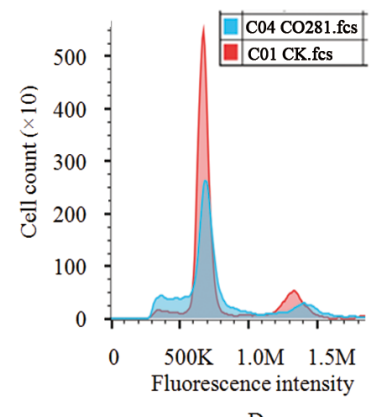

D

Figure 1 Sugarcane ploidy detection

Note: A: Mungo belonging to S. barberi; B: GSM56 belonging to S. spontaneum; C: WMBM09-11 belonging to Erianthus Michx.; D: Sugarcane hybrid cultivar Co281; Red peak: The fluorescence intensity of CK; Blue peak: The fluorescence intensity of the sample 
Molecular Plant Breeding 2019, Vol.10, No.12, 93-99

http://genbreedpublisher.com/index.php/mpb

Table 1 The data of ploidy detection

\begin{tabular}{|c|c|c|c|c|c|c|c|}
\hline Genus & Species & Clones & Ploidy & Genus & Species & Clones & Ploidy \\
\hline \multirow[t]{14}{*}{ Saccharum L. } & \multirow[t]{2}{*}{ S. officinarum } & Badila & 8.0 & \multirow[t]{6}{*}{ Related genera } & \multirow[t]{2}{*}{ Miscanthus Anderss } & M1 & 1.4 \\
\hline & & Kala Wa & 10.0 & & & M84-7 & 4.8 \\
\hline & \multirow[t]{2}{*}{ S. barberi } & Mungo & 8.0 & & \multirow[t]{4}{*}{ Narenga Bor } & GXN1 & 3.8 \\
\hline & & Pansahi & 16.8 & & & GXN2 & 5.2 \\
\hline & \multirow[t]{2}{*}{ S. sinense } & Uba & 9.8 & & & GXN5 & 4.7 \\
\hline & & Luzhe & 10.0 & & & $\mathrm{HJCN}$ & 3.6 \\
\hline & \multirow[t]{7}{*}{ S. spontaneum } & GSM56 & 7.7 & \multirow[t]{18}{*}{ Hybrid cultivar } & & POJ 2878 & 10.1 \\
\hline & & GSM84-24 & 8.6 & & & Co281 & 8.5 \\
\hline & & GSM85-2 & 9.2 & & & F134 & 8.6 \\
\hline & & GSM79-9 & 6.3 & & & CP49-50 & 9.4 \\
\hline & & YCGSM12 & 8.0 & & & ROC22 & 10.1 \\
\hline & & FJGSM2 & 8.0 & & & GT11 & 9.8 \\
\hline & & & & & & GT21 & 9.7 \\
\hline & S. robustum & S. robustum & 14.4 & & & GT28 & 10.7 \\
\hline Related & Erianthus & GXBM32 & 7.6 & & & GT29 & 9.1 \\
\hline \multirow[t]{9}{*}{ genera } & \multirow[t]{9}{*}{ Michx. } & XJZSBM3 & 7.6 & & & GT42 & 9.4 \\
\hline & & PXBM6 & 7.6 & & & GT43 & 9.2 \\
\hline & & WMBM09-11 & 7.6 & & & GT45 & 11.4 \\
\hline & & BM85-48 & 7.1 & & & GT46 & 8.2 \\
\hline & & BM52 & 7.9 & & & LC05-136 & 12.1 \\
\hline & & YFBM11 & 7.1 & & & YT93-159 & 12.3 \\
\hline & & SHBM4 & 7.8 & & & GF1 & 9.9 \\
\hline & & DZM1 & 3.3 & & & GF2 & 9.6 \\
\hline & & DZM2 & 3.8 & & & & \\
\hline
\end{tabular}

Miscanthus has two types $(1.4,4.8)$. In $S$. arundinaceum of Erianthus, there are four ploidy types $(7.1,7.6,7.8$, 7.9), while in E. rockii of Erianthus, there are two ploidy types $(3.3,3.8)$. The ploidy of Narenga is between 3.6 and 5.2. The ploidy of the related genera of sugarcane ranges from 1.4 to 7.9 , with the lowest ploidy in Miscanthus (1.4) and the highest in S. arundinaceum (7.9). The genetic background of the related genera with higher ploidy is relatively complex. The ploidy results demonstrate again that sugarcane is an aneuploid plant, especially the ploidy of these wild sugarcane germplasms also exists as aneuploidy.

\subsection{Ploidy identification of sugarcane hybrids}

From the data of ploidy detection (Table 1), we can see that compared with the related genera of sugarcane, the ploidy of sugarcane hybrids has more types and larger value which is between $8.2 \sim 12.3$. For example, the ploidy of POJ2878 and ROC22 is 10.1, Co281 is 8.5, F134 is 8.6, CP49-50 and GT42 is 9.4, GF1 is 9.9 and YT93-159 is 12.3. Sugarcane hybrids are the materials selected and bred from the conventional sugarcane breeding. They have more chromosomes and more complex genetic background. The ploidy of sugarcane hybrids should be larger than that of wild sugarcane varieties. The ploidy of sugarcane hybrids tested in this study was greater than that of related genera, among which nonuploid and decaploid were more common.

\section{Discussion}

\subsection{Ploidy analysis of sugarcane and its related genera}

In the complex of Saccharum, there are only reports about the ploidy of the typical tropical species Badila which is 8 at present (Whalen, 1991; Irvine, 1999; Wang et al., 2008; Wang et al., 2015b). This study is the first systematic study on ploidy of sugarcane and its related genera. In previous reports (Li, 2010, China Agriculture Press, pp.102-156), the chromosome numbers of the typical tropical species Badila, the atypical tropical species Kala Wa, S. barberi, S. sinense, S. spontaneum, and $S$. robustum were $2 \mathrm{n}=80,2 \mathrm{n}=124 \sim 126,2 \mathrm{n}=82 \sim 124$, $2 \mathrm{n}=116 \sim 118,2 \mathrm{n}=32 \sim 128$ and $2 \mathrm{n}=60$ or 80 , respectively. The results of this study indicated that except the ploidy 
of the typical tropical species Badila which was 8, the ploidy of the atypical tropical species Kala Wa was 10; the ploidy of $S$. barberi was 8 or 16.8 ; the ploidy of $S$. sinense was 10 or close to 10 ; the ploidy of $S$. spontaneum mainly was close to 8 ; and the ploidy of $S$. robustum was 14.4 . It was thus clear that the ploidy of the tested tropical species, S. barberi, S. sinense, S. spontaneum, and S. robustum was between 6.3 and 16.8 , and the agronomic traits among these species were also quite different. Whether the results of this study with large ploidy differences in Saccharum are related to their agronomic traits remains to be further studied. Among the tested materials, GSM79-9 of $S$. spontaneum has the lowest ploidy (6.3), while Pansahi of $S$. barberi has the highest ploidy (16.8). Most of the ploidy of $S$. spontaneum is about 8, indicating that most of the S. spontaneum species belong to octoploid. The chromosome number of $S$. robustum in Saccharum is relatively small, and other species have larger chromosome number, but $S$. robustum maintains a high ploidy level. Whether this indicates that $S$. robustum has more relatively complex genetic background information needs further investigation.

The results of this study showed that in the related genera of Saccharum, Miscanthus had the lowest ploidy (1.4). The genetic background of this material was relatively simple, but Miscanthus also contained species which had the ploidy of 4.8. Previous studies had shown that the chromosome number of Miscanthus was $2 \mathrm{n}=38 \sim 114$ (Cai et al., 2002; Li et al., 2010, China Agriculture Press, pp.102-156). Chromosome numbers ranged from low to high, which might be the main reason for the ploidy types of 1.4 and 4.8 in Miscanthus. Narenga is a wild species in sugarcane complex, which has small chromosome number $(2 \mathrm{n}=30)$ (Cai et al., 2002; Li, 2010, China Agriculture Press, pp.102-156). The ploidy of Narenga mainly concentrates between 3.8 and 5.2, with little difference, which may be related to its relatively stable chromosome number. Most $S$. arundinaceum of Erianthus ( $2 \mathrm{n}=60$ mainly) (Cai et al., 2002) has the ploidy of 7 8, inferring that $S$. arundinaceum should belong to the species with stable ploidy.

In the hybrids of sugarcane, there are many ploidy types and the ploidy is relatively high, with the variation between $8.3 \sim 12.3$. The reason may be that these hybrids are the varieties (lines) produced in the process of sugarcane "Nobilization" breeding. After hybridization, the number of chromosomes is more than 100. They contain S. officinarum, S. barberi and S. sinense (Li, 2010, China Agriculture Press, pp.102-156), and have relatively more heterologous genetic materials, and the genetic background is more complex, which leads to the increase of ploidy size and ploidy types. For instance, POJ2878 is the hybrid progeny of $S$. spontaneum and $S$. officinarum, which aggregates the genetic background of the two species. The ploidy of POJ 2878 is 10.1 , which is higher than the ploidy of the tested $S$. spontaneum species. However, there is also a special case, that is, the ploidy of the original species is higher than that of the hybrid varieties. For example, the ploidy of Pansahi of $S$. barberi is 16.8 , which is higher than that of all the cultivated species tested. Whether this indicates that sugarcane protospecies Pansahi also has complex genetic background needs further study.

The results of this study indicated that the ploidy of most sugarcane materials tested was aneuploidy, which again illustrated that sugarcane might be an aneuploid plant with complex genetic background. Generally speaking, the higher the ploidy, the more the genome and the more complex the genetic background. Therefore, in the routine sugarcane breeding, it is suggested that the ploidy of the materials used should be clearly understood before the intraspecific and interspecific distant hybridization. The efficiency of genetic improvement of sugarcane varieties could be improved more effectively by selecting materials with high or low ploidy according to breeding objectives.

\subsection{Feasibility of flow cytometry in ploidy identification of sugarcane}

Flow cytometry has been successfully applied to sugarcane. Previous studies have used this technique to analyze genome size of different sugarcane varieties (lines) (Oliveira et al., 2015; Mondal et al., 2017), but no report has been reported to identify ploidy of sugarcane. Sugarcane is an allopolyploid plant. Except for some protospecies, such as Badila $(2 \mathrm{n}=80)$, Narenga $(2 \mathrm{n}=30)$, Saccharum arundinaceum $(2 \mathrm{n}=60)$, other genera and species of sugarcane have many chromosomes, and there is no complete unified number. The chromosome number of a 
sugarcane material could only be represented by the mode number (Cai et al., 2002; Li, 2010, China Agriculture Press, pp.102-156). The determination of the ploidy of sugarcane by morphological identification, physiological and biochemical index identification, fertility status identification and cytological identification is cumbersome and difficult.

Flow cytometry is based on the analysis of nuclear DNA content detected to determine ploidy. The more cells and the higher DNA content were analyzed, the more accurate the results were. In this research, the detected cell number of Badila, GXN1, Pansahi, Mungo, Luzhe and POJ2878 was 14 891, 15 824, 8 862, 5 193, 6522 and 8 291, respectively. The detected cell number in the tested materials was all over 5000 , which was consistent with previous studies on other crops (Wu et al., 2014; Yang et al., 2017). Therefore, the results obtained in this study could be more accurate. Flow cytometry provides a reliable and rapid method for ploidy identification of heteroploid plants such as sugarcane.

\section{Materials and Methods}

\subsection{Experimental materials}

In this study, 46 sugarcane materials and its related genera were used (Table 2). Among them, there were $13 S$. officinarum, S. barberi, S. sinense, S. spontaneum and S. robustum, 16 Erianthus, Miscanthus and Narenga of related genera, and 17 hybrid varieties. The materials were conserved in Hainan Sugarcane Hybrid Breeding Base of Sugarcane Research Center of Chinese Academy of Agricultural Sciences and Sugarcane Germplasm Resources Nursery of Sugarcane Research Institute of Guangxi Academy of Agricultural Sciences. The stems of the materials were collected on $14^{\text {th }}$ July, 2017 and placed in ice boxes. After cleaning in the laboratory, the materials were put in a refrigerator at $4^{\circ} \mathrm{C}$ for use. The reagents used were as follows: solution A: $10 \mathrm{mmol} / \mathrm{L}$ $\mathrm{MgSO}_{4} \cdot 7 \mathrm{H}_{2} \mathrm{O} 0.246 \mathrm{~g}, 50 \mathrm{mmol} / \mathrm{L} \mathrm{KCl} 0.370 \mathrm{~g}$ and $5 \mathrm{mmol} / \mathrm{L}$ Hepes $120 \mathrm{~g}$. The volume of solution A was set to

Table 2 Names of tested sugarcane clones

\begin{tabular}{|c|c|c|c|c|c|c|c|}
\hline Genus & Species & Clones & Origins & Genus & Species & Clones & Origins \\
\hline \multirow[t]{14}{*}{ Saccharum L. } & \multirow[t]{2}{*}{ S. officinarum } & Badila & Unknon & \multirow{6}{*}{$\begin{array}{l}\text { Related } \\
\text { genera }\end{array}$} & Miscanthus & M1 & Guangxi \\
\hline & & Kala Wa & Unknon & & Anderss. & M84-7 & Yunnan \\
\hline & \multirow[t]{2}{*}{ S. barberi } & Mungo & India & & \multirow[t]{22}{*}{ Narenga Bor } & GXN1 & Guangxi \\
\hline & & Pansahi & India & & & GXN2 & Guangxi \\
\hline & \multirow[t]{2}{*}{ S. sinense } & Uba & Unknon & & & GXN5 & Guangxi \\
\hline & & Luzhe & Sichuan & & & HJCN & Guangxi \\
\hline & \multirow[t]{7}{*}{ S. spontaneum } & GSM56 & Guangxi & \multirow[t]{7}{*}{ Variety } & & POJ2878 & Jawa \\
\hline & & GSM84-24 & Guangxi & & & Co281 & India \\
\hline & & GSM85-2 & Guangxi & & & F134 & Taiwan \\
\hline & & GSM79-9 & Guangxi & & & СР49-50 & America \\
\hline & & YCGSM12 & Hainan & & & ROC22 & Taiwan \\
\hline & & FJGSM2 & Fujian & & & GT11 & Guangxi \\
\hline & & & & & & GT21 & Guangxi \\
\hline & S. robustum & S. Robustum & Unknon & & & GT28 & Guangxi \\
\hline \multirow[t]{10}{*}{ Related genera } & Erianthus & GXBM32 & Guangxi & & & GT29 & Guangxi \\
\hline & \multirow[t]{9}{*}{ Michx. } & XJZSBM3 & Guangxi & & & GT42 & Guangxi \\
\hline & & PXBM6 & Guangxi & & & GT43 & Guangxi \\
\hline & & WMBM09-11 & Guangxi & & & GT45 & Guangxi \\
\hline & & BM85-48 & Guangxi & & & GT46 & Guangxi \\
\hline & & BM52 & Guangxi & & & LC05-136 & Guangxi \\
\hline & & YFBM11 & Guangxi & & & YT93-159 & Guangdong \\
\hline & & SHBM4 & Guangxi & & & GF1 & Fiji \\
\hline & & DZM1 & Yunnan & & & GF2 & Fiji \\
\hline & & DZM2 & Yunnan & & & & \\
\hline
\end{tabular}


$100 \mathrm{~mL}$ by $\mathrm{ddH}_{2} \mathrm{O}$ and the $\mathrm{pH}$ was adjusted to 8.0 . Solution B: $375 \mu \mathrm{L}$ Triton $\mathrm{X}-100$ was added to $14.3 \mathrm{~mL} \mathrm{~A}$ buffer solution, and then $300 \mu \mathrm{L}$ PI and $15 \mathrm{mg}$ DTT were added to the mixture. Solution C: $7.5 \mu \mathrm{L}$ RNAase was added to and mixed with $3 \mathrm{~mL}$ solution $\mathrm{B}$, which was then stored at $4^{\circ} \mathrm{C}$ for use. The main instrument used was flow cytometry BD Accuri C6 plus.

\subsection{Ploidy detection}

Pull out the outer leaves of sugarcane slightly and take $50 \mathrm{mg}$ of the inner tip tissue; Add $1 \mathrm{~mL}$ solution B and cut up the tip $(<0.5 \mathrm{~mm})$; The mixture was screened to EP tube through $33 \mu \mathrm{m} \mathrm{screen} \mathrm{mesh;} 13000 \mathrm{r} / \mathrm{min}$ centrifugation for $20 \mathrm{~s}$, discarding supernatant; Resuspension with $200 \mu \mathrm{L}$ solution $\mathrm{C}$ and incubation at $37^{\circ} \mathrm{C}$ for $15 \mathrm{~min}$. Flow cytometry BD Accuri C6 plus was used to detect and the threshold was 5000 . FSC-SSC was used to construct scatter diagram, and main cell mass was circled. FL2-A-FL2-H was used to construct scatter diagram, and PI-positive and non-adherent cells in the upper right corner were circled. Then FL2-A was used to construct histogram and abscissa was changed to logarithmic form. Set Badila (octaploid) as the control, and the ploidy of the tested materials was calculated according to sample ploidy $=($ Control ploidy $\times$ Peak fluorescence intensity of samples)/Peak fluorescence intensity of internal reference (Oliveira et al., 2015; Mondal et al., 2017).

\section{Authors' Contributions}

LXH was the designer and executor of the experiment in this study; ZRH, GYY, WJJ and QHP participated in experiment implement and results analysis; DWX was involved in materials planting; HDL and LYR were responsible for the project conception, test design and paper revision. All authors read and agreed to the final manuscript.

\section{Acknowledgments}

This research was jointly supported by "863" Project (2013AA102604), The National Natural Science Foundation of China (31101195), Special Project of Guangxi “Bagui Scholars” and Specially Invite Experts, Key Laboratory Project of Sugarcane Genetic Improvement in Guangxi (16-389-18), Guangxi Innovation Team Project of National Industrial System (gjnytxgxcxtd -03-01) and Fund of Guangxi Academy of Agricultural Sciences (Guinongke 2016JM07, 2018YT02).

\section{References}

Bremer G., 1924, The cytology of sugarcane. A cytological investigation of some cultivated kinds and their parents, Genatica, 6: 497-525 https://doi.org/10.1007/BF01501148

Cai Q., Wen J.C., Fan Y.H., Wang L.P., and Ma L., 2002, Chromosome anasysis of Saccharum L. and related plants, Xinan Nongye Xuebao (Southwest China Journal of Agricultural Sciences), 15(2): 16-19

Chen Y., Wang Z.Q., Fu Z.W., Yang Y.T., Guo J.L., Su Y.C., and Xu L.P., 2015, Cloning and expression analysis of metallothionein gene ScMT2-1-4 in sugarcane, Jiyinzuxue Yu Yingyong Shengwuxue (Genomics and Applied Biology), 34(2): 357-364

Grivet L., and Arruda P., 2001, Sugarcane genomics: depicting the complex genome of an important tropical crop, Curr. Opin. Plant Biol., 5(2): 122-127 https://doi.org/10.1016/S1369-5266(02)00234-0

Hang Y.J., Fu C., Lin W.L., Liu S.M., Gao J.H., Deng Z.H., Huang Z.X., Lin Y.Q., and Chen R.K., 2015, Genetic analysis of chromosome in 3 BC 1 clones from the distant crossing between Saccharum spp. and Erianthus arundinaceus, Redai Zuowu Xuebao (Chinese Journal of Tropical Crops), 36(1): 53-58

Hu Y., Li Y., Huang Y.Z., and Liu P.W., 2016, Genetic diversity evaluation of sugarcane varieties using SSR and RAPD markers, Jiyinzuxue Yu Yingyong Shengwuxue (Genomics and Applied Biology), 35(9): 2494-2503

Irvine J.E., 1999, Saccharum species as horticultural classes, Theor. Appl. Genet., 98(2): 186-194 https://doi.org/10.1007/s001220051057

Jin L., Xu W.W., Li X.B., Liu J.X., Tian D.Q., Ge Y.Y., Pan X.Y., and Wang W.Y., 2016, Application of DNA flow cytomutry to plant genetics and breeding, Zhongguo Xibao Shengweuxue Xuebao (Chinese Journal of Cell Biology), 38(2): 225-234

Li X.J., Liu H.B., Lin X.Q., Wu Z.D., Xu C.H., and Liu X.L., 2015, In silico cloning and bioinformatics analysis of KNOX gene in sugarcane (Sckn1), Jiyinzuxue Yu Yingyong Shengwuxue (Genomics and Applied Biology), 34(1): 136-142

Li Y.R., Song X.P., Wu J.M., Li C.N., Liang Q., Liu X.H., Wang W.Z., Tan H.W., and Yang L.T., 2016, Sugar industry and improved sugarcane farming technologies in China, Sugar Tech, 18(6): 603-611 https://doi.org/10.1007/s12355-016-0480-8

Liu X.H., Fang F.X., Gao Y.J., Zhang R.H., Song H.Z., Yang R.Z., Fang W.K., Duan W.X., Luo T., Zhang G.M., and Li Y.R., 2012a, Identification and genetic analysis of hybrid from cross between Erianthus arundinacius (Retz.) Jesws. and Saccharum spontaneum L., Zuowu Xuebao (Acta Agronomica Sinica), 38(5): 914-920 https://doi.org/10.3724/SP.J.1006.2012.00914

Liu X.H., Fang F.X., Zhang R.H., Song H.Z., Yang R.Z., Gao Y.J., Lei J.C., Luo T., Duan W.X., Zhang G.M., and Li Y.R., 2012b, Identification of progenies 
from sugarcane $\times$ Narenga porphyrocoma (Hance) Bor. by SSR marker, Xinan Nongye Xuebao (Southwest China Journal of Agricultural Sciences), 25(1): $38-42$

Liu X.H., Song H.Z., Zhang G.M., Duan W.X., Zhang R.H., and Li Y.R., 2017, Phenotypic variation and genetic diversity in the collections of Erianthus Arundinaceus (Retz.) Jesw, Sugar Tech, 19(4): 359-367 https://doi.org/10.1007/s12355-016-0475-5

Mondal A., Ghosal S.K., Pal T., and De K.K., 2017, Determination of DNA content and relative 2C genome sizes of some promising commercial varieties of sugarcane using flow cytometer, Current Botany, 8: 66-73 https://doi.org/10.19071/cb.2017.v8.3207

Oliveira A.C., Pasqual M., Bruzi A.T., Pio L.A., Mendonça P.M., and Soares J.D., 2015, Flow cytometry reliability analysis and variations in sugarcane DNA content, Genet. Mol. Res., 14(2): 7172-7183 https://doi.org/10.4238/2015.June.29.11 PMid:26125928

Qin Y.H., Xu X., and Wang C.T., 2014, Measurement of DNA content and ploidy of rice cell nucleus suspensions by flow cytomety, Zhongnan Minzu Daxue Xuebao (Journal of South-Central University for Nationalities (Natural Science Edition)), 33(1): 28-30

Wang P., Yu F., Huang Y.J., Chen S.H., Jing Y.F., and Deng Z.H., 2015a, Determination of authenticity of Saccharum officinarum clones by chromosome numbers, Yaredai Nongye Yanjiu (Subtropical Agriculture Research), 11(3): 160-163

Wang P., Yu F., Huang Y.J., Chen S.Y., and Deng Z.H., 2015b, Physical localization of 5S rDNA on the chromosomes of different ploidy Saccharum spontaneum, Jiyinzuxue Yu Yingyong Shengwuxue (Genomics and Applied Biology), 34(8): 1761-1768Wang Y., Gao H.Q., Zhuang N.S., Huang D.Y., and Ma S., 2008, Karyotype analysis on Sacchatum spont. YC No.11 and Badila, Zhongguo Nongxue Tongbao (Chinese Agricultural Science Bulletin), 24(3): $52-57$

Whalen M.D., 1991, Taxonomy of Saccharum (Poaceae), Baileya, 23(3): 109-125

Wu Y.Q., Zhou X.M., Chen L., Cheng H.H., Li Y.S., Wu Y.J., and Zhao Y.H., 2014, Nuclear DNA content and chromosome ploidy determination of sweet cherry rootstock by flow cytometry, Guoshu Xuebao (Journal of Fruit Science), 31(S): 48-52

Xu Y., Wang Z.Q., Wu Q.B., Chen Y., Yang C.C., Feng M.X., and Su Y.C., 2015, Cloning, sequencing and expression analysis of chitinase gene ScChi IV1 from sugarcane, Jiyinzuxue Yu Yingyong Shengwuxue (Genomics and Applied Biology), 34(6): 1258-1266

Yang J., Song Q.X., Ning J.Q., Sun Z.Y., Qian Y.H., and Jiao F., 2017, Establishment of Morus L. chromosome ploidy identification method using flow cytometry, Canye Kexue (Science of Sericulture), 43(1): 8-17

Zhao Q., Zhang Q., Zhou P., Lin F., and Fang Y.M., 2016, Analysis of DNA C-value and ploidy of five species in Magnoliaceae, Zhiwu Yanjiu (Bulletin of Botanical Research), 36(6): 853-859 